\title{
A-Z of nutritional supplements: dietary supplements, sports nutrition foods and ergogenic aids for health and performance-Part 20
}

\author{
K Currell, ${ }^{1}$ W Derave, ${ }^{2}$ I Everaert, ${ }^{2}$ L McNaughton, ${ }^{3}$ G Slater, ${ }^{4}$ L M Burke, ${ }^{5}$ S J Stear, ${ }^{6}$ \\ $\mathrm{L} \mathrm{M} \mathrm{Castell}^{7}$
}

'English Institute of Sport, Bisham Abbey Performance Centre, Marlow, Buckinghamshire, UK ${ }^{2}$ Department of Movement and Sports Sciences, Ghent University, Ghent, Belgium ${ }^{3}$ Faculty of Health Sciences and Medicine, Bond University, Queensland, Australia

${ }^{4}$ Faculty of Science, Health and Education, University of the Sunshine Coast, Maroochydore, Queensland, Australia

${ }^{5}$ Department of Sports Nutrition, Australian Institute of Sport, Belconnen, Canberra, Australia

${ }^{6}$ Performance Influencers Limited, London, UK ${ }^{7}$ University of Oxford, Green Templeton College, Oxford, UK

Corresponding to L M Castell, University of Oxford, Green Templeton College, Woodstock Road, Oxford OX2 6HG, UK; lindy.castell@gtc.ox.ac.uk

Accepted 9 March 2011

\section{INTRODUCTORY REMARKS}

As usual, the alphabet throws together a mixture of supplements with different levels of popularity and scientific support. Part 20 covers some rarely reported, studied and/or little used supplements in sport: glycine, histidine and inosine. The majority of human studies of supplementation with the essential amino acid histidine has involved clinical work. In terms of athletic performance, there is current interest in supplementation strategies to increase muscle content of the histidine-containing dipeptide (HCD), carnosine. Despite some interest in the use of a chicken breast extract (CBEX) described in this article, most of the focus in this area involves $\beta$-alanine supplementation (covered in part 5). There was some interest in inosine as an ergogenic aid in the 1990s but it appears not to have been studied since then. Meanwhile, there appears little role for glycine supplementation in sport although some interest in glycine-containing compounds is possible. $\beta$-Hydroxymethyl $\beta$-butyrate (HMB) is much more well known, with marketing usually targeting bodybuilders.

\section{GLYCINE \\ K Currell}

Glycine is the smallest amino acid; it is non-essential and can be synthesised from serine. Glycine is present in most proteins and is particularly highly concentrated in collagen. Consequently, one of the highest food sources of glycine is gelatin. Glycine is also one of the three amino acid components of glutathione, which is a key component of the body's defences against oxidative stress; however, it is thought that glycine availability is not the limiting step in glutathione synthesis. Glycine ingestion increases plasma concentrations of insulin in a similar way to other amino acids. ${ }^{1}$ Glycine is also an inhibitory neurotransmitter.

There is little research on supplementation with glycine. Research has looked at its potential role in decreasing inflammation. ${ }^{2}$ Sport specific research has focused on combining glycine with other nutrients. Glycine-propionyl-Lcarnitine (GPLC) has been shown to influence exercise performance, ${ }^{3}$ decrease oxidative stress ${ }^{4}$ and potentially increase vasodilation through increases in plasma nitrate. ${ }^{4}$ At present, there is insufficient evidence to suggest the use of glycine as a supplement to enhance sporting performance. However, further research on the effectiveness of GPLC is warranted.

\section{HISTIDINE-CONTAINING DIPEPTIDES W Derave and I Everaert}

Carnosine ( $\beta$-alanyl-L-histidine) andits methylated analogues anserine ( $\beta$-alanyl- $\mathrm{N}_{1}$-methylhistidine) and balenine ( $\beta$-alanyl- $\mathrm{N}_{3}$-methylhistidine) are HCDs present abundantly in mammalian skeletal muscles. Carnosine is the only HCD found in human skeletal muscles, whereas all three HCDs are present in the omnivorous human diet. In an attempt to understand the role of carnosine in human muscle, Harris et at searched for a carnosine loading protocol. They showed that $\beta$-alanine supplementation (4-6 g/day) for several weeks (4-10 weeks) resulted in elevated muscle carnosine levels (up to $80 \%$ ). $\beta$-Alanine seems to be without adverse effects if the dose of 10 $\mathrm{mg} / \mathrm{kg}$ body weight per 2 -h interval, which can lead to paraesthesia, is not exceeded. ${ }^{5}$ Hill et al ${ }^{6}$ showed that carnosine loading leads to better performance during high-intensity exercise (cycling at $110 \%$ of $W_{\max }$ to exhaustion). With the availability of more recent studies, it becomes evident that mostly high-intensity efforts that last several minutes experience a positive influence of $\beta$-alanine supplementation. Indeed, $\beta$-alanine was not ergogenic for repeated sprint performance $(10 \times 5$ s sprint $),{ }^{7}$ while both a simulated $2000-\mathrm{m}$ rowing race $( \pm 6 \mathrm{~min})^{8}$ and the sprint at the end of 2 -h simulated cycling race ${ }^{9}$ were improved by $\beta$-alanine. It is plausible that high-intensity performance is affected in long-term vegetarians, as they are characterised with lower muscle carnosine levels $(-26 \%)$. The ergogenic mechanism of $\beta$-alanine may reside in the attenuation of acidosis through the proton-buffering capacity of carnosine, whereas other physiological properties of carnosine (antioxidant, calcium sensitisation) cannot be excluded at present. ${ }^{10}$

Besides $\beta$-alanine supplementation, CBEX is also used, mainly in Japan, to elevate muscle carnosine stores. CBEX, obtained via hot water extraction of chicken breast, is a rich source of HCD, like anserine $(1.4 \mathrm{~g} / 100 \mathrm{ml})$ and carnosine $(0.6 \mathrm{~g} / 100 \mathrm{ml})$. An increase in the muscle carnosine content is likely to occur as a result of chronic CBEX supplementation. Long-term CBEX supplementation enhanced the time to exhaustion at the last spurt of a relatively high-intensity endurance performance. ${ }^{11}$ Suzuki et a $1^{12}$ showed that the acute supplementation with CBEX (0.4 g carnosine+1.1 g anserine) $30 \mathrm{~min}$ before $10 \times 5 \mathrm{~s}$ repeated sprints, decreased the bicarbonate buffering in blood but did not affect performance. The effect of acute supplementation 
with HCD on blood buffering and high-intensity exercise performance needs further investigation.

In conclusion, an increment in muscle carnosine levels, either by chronic $\beta$-alanine or CBEX supplementation, seems to be ergogenic mainly in high-intensity exercise lasting several minutes.

\section{INOSINE \\ L McNaughton}

Inosine is a nucleoside formed when hypoxanthine is attached to a ribose ring (also known as a riobfuranose) via a $\beta-\mathrm{N}_{9}$-glycosidic bond. Inosine plays a role in several metabolic functions including increasing red blood cell concentrations of 2,3-diphosphoglycerate (2,3-DPG), which is involved in oxygen transport. ${ }^{13}$ It may also potentiate the action of endogenously formed adenosine and inhibit its uptake and clearance. It has been proposed to enhance exercise performance via the effects on 2,3-DPG or by an increase in ATP concentrations. ${ }^{14}$

Little scientific investigation has been conducted on inosine as an ergogenic aid and few peer-reviewed papers could be found. The available studies involving trained individuals investigated chronic intakes of large doses of inosine (eg, 5-10 $000 \mathrm{mg} / \mathrm{day}$ ), but these protocols did not provide an ergogenic effect for endurance ${ }^{1516}$ or sprint activities. ${ }^{17}$ It is suggested that high-dose inosine, a uric acid precursor, combined with high urinary excretion, could be detrimental and result in kidney stones or acute renal failure. ${ }^{17}$ In summary, there appears to be little support for the use of inosine as an ergogenic aid though it is still used in some over-the-counter fitness products. There are continuing clinical trials that may indicate a future therapeutic effect as an antioxidant for exercise.

\section{HYDROXYMETHYL BUTYRATE \\ G Slater}

HMB is a metabolite of the essential branched chain amino acid leucine, via $\alpha$-ketoisocaproate, the transamination product of leucine. Approximately $2-10 \%$ of leucine oxidation proceeds to HMB. Much initial research on HMB focused on animals, assessing effects on immune function, morbidity and mortality, colostral milk fat content, growth rates, safety and toxicity. Despite unconvincing results in animal research, HMB supplementation was used in humans in the mid-1990s on the presumption that it might enhance gains in muscle size and strength while reducing muscle damage and soreness associated with resistance training, ${ }^{18}$ and possibly also enhance aerobic capacity.

Supplementation with either 1.5 or $3.0 \mathrm{~g}$ /day of HMB had a favourable impact on indirect indices of muscle protein breakdown and muscle damage, with concomitant trends for enhanced strength and skeletal muscle hypertrophy. ${ }^{18}$ Consequently, the popularity of HMB supplementation increased dramatically, becoming one of the top supplements used by athletes in the late $1990 \mathrm{~s} .{ }^{19}$ More recently, interest in HMB supplementation among athletes has probably declined. Despite this, HMB research reports within the sports environment continue to emerge. There are several recent $\mathrm{HMB}$ reviews, ${ }^{20} 21$ with results of resistance training research from 2001 to 2007 consolidated into two meta-analyses. ${ }^{22}{ }^{23}$ Nissen and Sharp ${ }^{22}$ concluded that HMB supplementation augmented lean mass and strength gains associated with resistance training, although the magnitude of effect was trivial $(0.28 \%$ increase in lean mass gain per week). Rowlands and Thomson ${ }^{23}$ identified similar small benefits from HMB supplementation in untrained males but effects were trivial for strength and non-existent for body composition in trained lifters.

This disparity in responsiveness to HMB supplementation relative to resistance training status might be expected, given the suppression in skeletal muscle protein breakdown as a consequence of resistance training adaptations. ${ }^{24}$ Furthermore, if $\mathrm{HMB}$ does enhance net protein balance following resistance training as a consequence of reducing protein degradation, any effect on adaptations is likely to be blunted compared with interventions that enhance protein synthesis as the protein synthetic response is many times more sensitive to nutrition interventions than degradation. ${ }^{25}$ An exception may be in clinical conditions such as cancer in which skeletal muscle atrophy results from an elevation in skeletal muscle protein breakdown. ${ }^{26}$

Short-term HMB supplementation appears to be safe, with daily doses equivalent to approximately 6 g/day $(76 \mathrm{mg} / \mathrm{kg})$ having no impact on indices of hepatic, renal or immune function. ${ }^{20}$

Based on current available reports, the potential for HMB supplementation to enhance strength training adaptations appears to be small in previously untrained individuals and negligible in resistance-trained athletes. Given that the protein synthetic response is much more sensitive to nutrition interventions than protein breakdown, the resistance-trained athlete is advised to focus on proven strategies such as post-exercise ingestion of high biological value proteins rich in leucine to maximise adaptation to the resistance training stimulus.

\section{CONCLUDING COMMENTS}

While there is probably little reason to study (or take) glycine, histidine or inosine supplements, some investigation of other compounds containing these molecules may be warranted. In the case of histidine, there is good reason to try to enhance muscle storage of the HCD, carnosine, but the most common and effective supplement to achieve this is $\beta$-alanine rather than histidine or carnosine per se. Finally, there is evidence that supplementation with $\mathrm{HMB}$ offers some assistance in reducing the breakdown of muscle protein. However, the best application of this appears to be in clinical situations involving high levels of catabolism, such as cancer, rather than in athletic populations since strategies to increase muscle size and strength in resistance-trained groups are more effectively targeted at increasing protein synthesis.

\section{Competing interests None}

Provenance and peer review Commissioned; not externally peer reviewed.

\section{REFERENCES}

1. Gannon MC, Nuttall JA, Nuttall FQ. The metabolic response to glycine. Am J Clin Nutr 2002;76:1302-7.

2. Zhong Z, Wheeler MD, Li X, et al. L-Glycine: a novel anti-inflammatory, immunomodulatory, and cytoprotective agent. Curr Opin Clin Nutr Metab Care 2003;6:229-40.

3. Smith WA, Fry AC, Tschume LC, et al. Effect of glycine propionyl-L-carnitine on aerobic and anaerobic exercise performance. Int J Sport Nutr Exerc Metab 2008;18:19-36.

4. Bloomer RJ, Smith WA. Oxidative stress in response to aerobic and anaerobic power testing: influence of exercise training and carnitine supplementation. Res Sports Med 2009;17:1-16.

5. Harris RC, Tallon MJ, Dunnett M, et al. The absorption of orally supplied betaalanine and its effect on muscle carnosine synthesis in human vastus lateralis. Amino Acids 2006;30:279-89.

6. Hill CA, Harris RC, Kim HJ, et al. Influence of beta-alanine supplementation on skeletal muscle carnosine concentrations and high intensity cycling capacity. Amino Acids 2007;32:225-33. 
7. Sweeney KM, Wright GA, Glenn Brice A, et al. The effect of beta-alanine supplementation on power performance during repeated sprint activity. J Strength Cond Res 2010;24:79-87.

8. Baguet A, Bourgois J, Vanhee L, et al. Important role of muscle carnosine in rowing performance. J Appl Physiol 2010;109:1096-101.

9. Van Thienen R, Van Proeyen K, Vanden Eynde B, et al. Beta-alanine improves sprint performance in endurance cycling. Med Sci Sports Exerc 2009;41:898-903.

10. Derave W, Everaert I, Beeckman S, et al. Muscle carnosine metabolism and beta-alanine supplementation in relation to exercise and training. Sports Med 2010;40:247-63.

11. Maemura H, Goto K, Yoshioka T, et al. Effects of carnosine and anserine supplementation on relatively high intensity endurance. Int J Sport Health Sci 2006:4:86-94.

12. Suzuki Y, Nakao T, Maemura H, et al. Carnosine and anserine ingestion enhances contribution of nonbicarbonate buffering. Med Sci Sports Exerc 2006;38:334-8.

13. Valeri CR. Blood Banking and the Use of Frozen Blood Products. Cleveland, OH: CRC Press 1976.

14. Harmsen E, de Tombe PP, de Jong J, et al. Enhanced ATP and GTP synthesis from hypoxanthine or inosine after myocardial ischaemia. Am J Physiol 1984;246: H37-43.

15. Starling RD, Trappe TA, Short KR, et al. Effect of inosine supplementation on aerobic and anaerobic cycling performance. Med Sci Sports Exerc 1996;28:1193-8.

16. Williams MH, Kreider RB, Hunter DW, et al. Effect of inosine supplementation on 3-mile treadmill run performance and $\mathrm{VO}_{2}$ peak. Med Sci Sports Exerc 1990:22:517-22.
17. McNaughton L, Dalton B, Tarr J. Inosine supplementation has no effect on aerobic or anaerobic cycling performance. Int J Sports Nutr 1999;9:333-44.

18. Nissen S, Sharp R, Ray M, et al. Effect of leucine metabolite beta-hydroxy-betamethylbutyrate on muscle metabolism during resistance-exercise training. J Appl Physiol 1996;81:2095-104.

19. Sallis RE, Jones K. Dietary supplement use among college football players. Med Sci Sports Exerc 1999:31:S118.

20. Portal S, Eliakim A, Nemet D, et al. Effect of HMB supplementation on body composition, fitness, hormonal profile and muscle damage indices. J Pediatr Endocrinol Metab 2010;23:641-50.

21. Zanchi NE, Gerlinger-Romero F, Guimarães-Ferreira L, et al. HMB supplementation: clinical and athletic performance-related effects and mechanisms of action. Amino Acids 2011;40:1015-25.

22. Nissen SL, Sharp RL. Effect of dietary supplements on lean mass and strength gains with resistance exercise: a meta-analysis. J Appl Physiol 2003;94:651-9.

23. Rowlands DS, Thomson JS. Effects of beta-hydroxy-beta-methylbutyrate supplementation during resistance training on strength, body composition, and muscle damage in trained and untrained young men: a meta-analysis. J Strength Cond Res 2009;23:836-46.

24. Phillips SM, Tipton KD, Ferrando AA, et al. Resistance training reduces the acute exercise-induced increase in muscle protein turnover. Am J Physiol 1999;276:E118-24

25. Tang JE, Phillips SM. Maximizing muscle protein anabolism: the role of protein quality. Curr Opin Clin Nutr Metab Care 2009;12:66-71.

26. Lecker SH, Jagoe RT, Gilbert A, et al. Multiple types of skeletal muscle atrophy involve a common program of changes in gene expression. FASEB $J$ 2004; 18:39-51. 


\section{BJSM}

\section{A-Z of nutritional supplements: dietary supplements, sports nutrition foods and ergogenic aids for health and performance- Part 20}

K Currell, W Derave, I Everaert, et al.

Br J Sports Med 2011 45: 530-532

doi: $10.1136 /$ bjsports-2011-090020

Updated information and services can be found at:

http://bjsm.bmj.com/content/45/6/530.full.html

\section{These include:}

References This article cites 25 articles, 5 of which can be accessed free at: http://bjsm.bmj.com/content/45/6/530.full.html\#ref-list-1

Email alerting Receive free email alerts when new articles cite this article. Sign up in service the box at the top right corner of the online article.

Notes

To request permissions go to:

http://group.bmj.com/group/rights-licensing/permissions

To order reprints go to:

http://journals.bmj.com/cgi/reprintform

To subscribe to BMJ go to:

http://group.bmj.com/subscribe/ 